\title{
A Proposal for a Pilot Bilingual Bicultural Education Teacher Training
}

\author{
Chengping Liu $^{1}$ \\ ${ }^{1}$ Sichuan Minzu College, Kangding, Sichuan, China \\ Email: yyxliu@126.com
}

\begin{abstract}
Keywords: Ganzi Tibetan Autonomous Prefecture, Bilingual Bicultural Education, Teacher Training, Teaching Modes, Coping Strategies
\end{abstract}

\begin{abstract}
Bilingual bicultural education programs have played a significant role in the integration and development of multicultural communities in many parts of the world for a number of years with the field growing steadily in importance on a global scale. This article examines the processes of planning a pilot course in bilingual bicultural education for Sichuan Minzu College, which serves as the only university in the culturally diverse Ganzi Tibetan Autonomous Prefecture of Sichuan Province. It explains choices made by teaching staff of the Department of English involved in initial planning meetings and lists the range of teaching modes that were finally agreed upon. Perhaps of greater interest, however, are the many coping strategies that were necessary along the way.
\end{abstract}

\section{Introduction}

Bilingual bicultural education is neither a trend nor a fashion. It has been around for many years and is a field of growing global importance attracting the attention of policy makers, political, educational, and social. It is a field which promotes multilingualism through learning and teaching in more than one language, and it finds relevance where different cultures converge in a shared social space. Bilingual bicultural education focuses on the minority and seeks to benefit them. The use of more than one language in instruction calls for different ways of thinking about teaching in an increasingly multilingual and multicultural environment. My starting point was to consider the demographics of the area in which I work and, first and foremost, the historical relationships between the different ethnic groups of students on campus, which is itself a defining social or cultural context where people have to embrace, on a day to day basis, elements of two cultures.

A bilingual bicultural project, by definition, is able to build bridges and fill gaps. Such a program has a positive impact in a location like ours if there are sincere efforts by teachers working with bilingual bicultural methodology to cultivate talents that better serve the region in which the university is located. Therefore, with such thoughts in our heads, how do we move forward? How do we pave the way? What questions do we need to ask?

\section{Background}

Ganzi Tibetan Autonomous Prefecture was established in November 1950, accounts for one-third of the area of Sichuan Province. The territory is inhabited by Tibetan, Han, Yi, Hui, Qiang, Naxi, and twenty-five other ethnic groups; the main ethnic Tibetan group accounts for 78.9\% of the total population. Originally established in 1985 as Kangding Nationality Teachers' College, Sichuan Minzu College(SCMC) was upgraded in March 2009 to university status under the governmental auspices of Sichuan Province's Department of Education and now offers a range of full time study programs.

As stated before, Sichuan Minzu College upgraded in 2009 from a Teacher Training College. With such an upgrade, the general atmosphere on-campus is one of constructive change. Since 2009 there has been an extensive and ongoing investment in new buildings and infrastructure affecting all aspects of university life. Against such a background, it is appropriate that we also reassess our position in the region, our mission and our image. Quite simply, it is a time of great change and such a course is in keeping with the other improvement at our university.

It is true we have no experience at managing such a project; therefore, we need extensive 
dialogue with anyone and everyone who gets involved. We need to identify our strengths and our weaknesses and plan around them to our own great advantage. We need to tailor our bilingual bicultural course to meet our own specific needs. The term bilingual / bicultural education does not mean the same here as it does in New York where such work has been going on for decades with communities that have large numbers of Puerto Rican citizens. But the core values will be the same. Defining those core values will be the starting point, but it is clear that they must focus upon integration, cultivation of talents, and creation of employment opportunities, initially for the university population but ultimately for the wider community.

Bilingual / bicultural education around the world is about building dynamic communities and the purpose will be no different here. Our hopes are that the university becomes a local agent for change, doing its part to strengthen ties among the different groups represented locally by better meeting the needs of all who live, study, and work here and securing the university's place as a .provider of quality education for the socioeconomic development of the region. Initially, we are planning an elective course and the first one will be an introduction. Ultimately, the course will be offered as a major in the mainstream program.

The course participants will learn a set of skills that have direct relevance to the local community and the socio-cultural region beyond. The course will offer a set of skills that give participants advantages in the jobs market over others who do not possess bilingual / bicultural experience and skills. It will enable local people to build careers locally.

\section{Procedure}

In this project all aspects of teaching will be re-discussed, renegotiated, and rethought. We will work in groups of 20 for the purposes of input sessions, in groups of 7 for tutorials and individually for ongoing assessed assignments. The school will create learning spaces which enable meaningful interaction and learning to take place. Course participants will learn to work inclusively and follow an agenda that promotes equal opportunities for all students in the group. Communicative skills will be a priority and an atmosphere of active participation will be pursued.

In the average Chinese classroom, the teacher is the sole imparter of knowledge and students learn passively. Course participants will be taught to think about the role of teacher in a bi-cultural context, to ask questions and to set up language-learning activities without lecturing. They will be taught to encourage and elicit student input in a meaningful, inclusive way that reflects the needs of local student groups by going through the same processes themselves during study sessions. And course participants will attend activities that are culturally-based. They will learn how to plan lessons to include cultural perspectives. They will not teach grammar, writing, or reading.

How do We Find A Target Group for A Program of Bilingual Bicultural Education? In the first instance we will handpick the course participants according to our understanding in the Department of English of their existing skills mix. With one course behind us, we will have the confidence to open up the program more widely and offer it as an optional course on the same terms as other optional courses.

\section{Who will Be Involved?}

One project manager

One teacher--a native Tibetan speaker (tutor)

One teacher--a native Mandarin speaker (tutor)

One teacher--a native English speaker (language input)

One teacher (teaching skills)

Guest activity leaders (culture)

10 Tibetan and 10 Han Chinese students from the English Department

How Is The Program Managed? The project manager will be responsible for all administrative processes, including internal and external liaison. The foreign ESL teacher will devise and present workshops in English Language Structures. The local teacher will lecture on Lesson Planning and coordinate self-study.The Tibetan- and the Mandarin-speaking teachers will tutor small groups in Making Lessons Bicultural. The guest activity leaders will lead activities on Culture Matters. 
How do We Create A Syllabus, and What Form will It Take? The course, which is initially a pilot scheme, will be made up as follows: one lesson weekly of English Language Structures input, lectures on Lesson Planning, a continual self study program (Lesson Planning), a weekly tutorial on biculturalism in the classroom, one weekly Putonghua or Tibetan lessonm, one weekly activity and some teaching practice visits to local schools.

How will the Program Be Assessed. The project manager will recommend and seek grading approval based on the following guidelines:

The ESL teacher will run monthly informal progress checks on aspects of language, followed by an end of term multiple choice exam.

In teaching skills, the teacher will devise and coordinate a system of continual assessment of student written assignments.

Tutors will devise an appropriate system for the assessment of tutorials in due course.

Activity Leaders will assess an end-of-term essay on a cultural topic.

What about The Budget for The Project? The project manager will estimate project costs, be responsible for identifying sources of funding, and manage the budget on a daily basis. The main spending will be on course and reference materials.

Table 1 Lesson Plan Sample

\begin{tabular}{|c|c|c|c|}
\hline Context & \multicolumn{3}{|c|}{$\begin{array}{l}\text { Students Will Describe Their Daily Routines And Learn About The } \\
\text { Routines Of Each Other }\end{array}$} \\
\hline Prior & \multicolumn{3}{|c|}{ The Students Know Each Other In General As Classmates And } \\
\hline Knowledge & \multicolumn{3}{|c|}{ Share Much Experience Of The School System } \\
\hline Functional & \multicolumn{3}{|c|}{ Students Will Be Able To Talk About Their Routines And Explain Their Schedules } \\
\hline Objectives & \multicolumn{3}{|c|}{ And Will Learn Differences Of Other Households } \\
\hline Structures & \multicolumn{3}{|c|}{ Wake Up At/Get Washed/Dressed / Leave The House At / Have } \\
\hline Stage & Activity & Materials & Mi \\
\hline $\begin{array}{l}\text { Opening } \\
\text { (2 Minutes) }\end{array}$ & Sts A And B Give Prepared Welcome Speech & None & $\mathrm{Vl}$ \\
\hline $\begin{array}{l}\text { Setting Context } \\
5 \text { Minutes }\end{array}$ & $\begin{array}{l}\text { St B Acts Out Verbs Relating To Routine } \\
\text { St C Acts Out Objects Relating To Routine }\end{array}$ & Set Of Pictures & $\begin{array}{l}\mathrm{Vl} \\
\mathrm{V}\end{array}$ \\
\hline Comprehension Input & T Reviews The Vocabulary So Far With Yes / & $\begin{array}{l}\text { Sts A And B And } \\
\text { Their Set }\end{array}$ & V \\
\hline 5 Minutes & No Questions & Of Pictures. & $\mathrm{Vl}$ \\
\hline $\begin{array}{l}\text { Comprehension Game } \\
1\end{array}$ & Sts D And E Introduce A Game Of Charades & $\begin{array}{l}\text { Gestures And Body } \\
\text { language }\end{array}$ & V \\
\hline 3 Minutes & As Pair Work, A B & $\begin{array}{l}\text { For Routine } \\
\text { Activities }\end{array}$ & $\mathrm{Vl}$ \\
\hline $\begin{array}{l}\text { Comprehension Game } \\
2\end{array}$ & Students Change Roles B A & $\begin{array}{l}\text { Gestures And Body } \\
\text { Language }\end{array}$ & $\mathrm{V}$ \\
\hline 3 Minutes & & $\begin{array}{l}\text { For Routine } \\
\text { Activities }\end{array}$ & $\mathrm{Vl}$ \\
\hline $\begin{array}{l}\text { Comprehension Game } \\
3\end{array}$ & Students E And F Introduce A Different & $\begin{array}{l}\text { Set Of Pictures } \\
\text { For Each Pair }\end{array}$ & V \\
\hline 3 Minutes & $\begin{array}{l}\text { Game In Which The Class Puts Pictures Into } \\
\text { Sequence To Create A Routine }\end{array}$ & & $\mathrm{Vl}$ \\
\hline Teacher Input & T Holds Activity Cards In One Hand And Time & Activity Pictures & $\mathrm{V}$ \\
\hline 3 Minutes & $\begin{array}{l}\text { Cards In The Other. } \\
\text { T Helps Students To Make Sentences. }\end{array}$ & Clock Pictures & $\begin{array}{l}\mathrm{Vl} \\
\mathrm{Lm}\end{array}$ \\
\hline $\begin{array}{l}\text { Practice } \\
5 \text { Minutes }\end{array}$ & $\begin{array}{l}\text { Pairs Create Storyboards To Describe Their } \\
\text { Routines. }\end{array}$ & $\begin{array}{l}\text { Paper } \\
\text { Pencils }\end{array}$ & $\begin{array}{l}\text { Inter } \\
\mathrm{Vl}\end{array}$ \\
\hline & Speak The Routines Out Loud In Pairs. & & $\mathrm{Lm}$ \\
\hline $\begin{array}{l}\text { Teacher Led } \\
\text { Discussion }\end{array}$ & Discussion Highlighting Differences In & None & Intra \\
\hline 5 Minutes & Routine That Might Be Culture Based & & $\mathrm{Vl}$ \\
\hline Homework $2 \mathrm{M}$ & T Outlines A Written Homework Exercise. & None & $\mathrm{Vl}$ \\
\hline Closing 1 Minute & Students G And E Deliver The Farewell Speech & Noine & $\mathrm{Vl}$ \\
\hline
\end{tabular}




\section{Planning Lessons}

Course participants will learn to plan lessons that are in essence ESL lessons for young learners, featuring games and a range of enjoyable activities. When the project finally gets to local schools, the initial aims will be more about fun than fluency. Below is an example of a lesson plan created by a course participant.

Prior to the lesson Students A-E have tasks to prepare. The speeches need to be devised and rehearsed, preferably without writing. Activity cards and clock cards have to be made.

Here, $\mathrm{MI}=$ multiple intelligences, inter = interpersonal, $\mathrm{VL}=$ verbal linguistic, $\mathrm{LM}=$ logical mathematical, and $\mathrm{V}=$ visual.

\section{Conclusion}

The bilingual bicultural Education decision was made at the provincial level and the planning process is being coordinated by members of the Department of English, involving staff of the Department of Chinese and the Department of Tibetan Literature. The ambitions for the course are far-reaching: to raise the image and profile of the university within Ganzi Prefecture; to better fit the needs of local communities; to provide training that is relevant to the lives of course participants; and to train bilingual bicultural teachers for the future. This paper has laid out the processes involved in the initial planning stages and has given a rationale for the path taken.

\section{Acknowledgements}

The author wishes to acknowledge the financial support from the Sichuan 2011 Higher Education Quality Program Fund. The project undertaken by the author is entitled "Bilingual Bicultural Teaching Reform on English and Tibetan Language Learning of English Majors "(Document code: SC (2011〕 580). This article is one of the phased objectives of the project.

\section{References}

[1] Benet-MartíNez V., Haritatos J. (2005) Bicultural Identity Integration (BII): Components and Psychosocial Antecedents. Journal of Personality. 73, 1015-1050.

[2] Bob Anderson, \& Anwei Feng. (2009). A Comparison Of Trilingual Education Polices for Ethnic Minorities In China, Compare: A Journal Of Comparative and International Education, 39:3, 321-333.

[3] Cummins, Jim (2005).“Teaching for Cross-Language Transfer in Dual Language Education: Possibilities and Pitfalls.

[4] Feng, A. (2005). Bilingualism for the Minor Or The Major? An Evaluative Analysis of Parallel Conceptions in China. International Journal of Bilingual Education\&Bilingualism, 8(6), 529-551.

[5] Lambert, J. (2011). Multi-Language Identity Texts + Internet Technology: A Case Study from Guza, China. In Cummins, J. and Early, M. (Eds.) Identity Texts: The Collaborative Creation of Power In Multilingual Schools. Trentham Books: London. 101-107.

[6] Tsung, L. \& Cruickshank, K. (2009). Mother Tongue and Bilingual Minority Education in China. International Journal of Bilingual Education and Bilingualism, 12 (5), 549-563.

[7] Yuan, Y. (2002). Attitude and Motivation for English Language Learning of Ethnic Minority Students in China. Empirical Study of Minority Students Attitudes and Motives. Shanghai Foreign Language Education Press.

[8] Zhenzhou, Z. (2010). China's Ethnic Dilemma: Ethnic Minority Education. Chinese Education \& Society,43(1), 3-11. 
[9] Zhu, Z. (2007). Ethnic Identity Construction in The Schooling Context. Chinese Education \& Society, 40(2), 38-59.

[10] Zhu, Z. (2010). Higher Education Access and Equality Among Ethnic Minorities in China. Chinese Education And Society, 43(1), 12-23. Doi:10.2753/CED1061-1932430101

[11] Seth J. Schwartz, Jennifer B. Unger. Biculturalism And Context: What Is Biculturalism, and When Is It Adaptive? Http://Www.Ncbi.Nlm.Nih.Gov/Pmc/Articles/PMC2840244/ 